\title{
Purification and characterization of angiotensin converting enzyme-inhibitory peptides derived from Stichopus horrens: stability study against the ACE and inhibition kinetics
}

\begin{abstract}
Stichopus horrens is the most popular species of sea cucumber due to strong beliefs of its numerous medicinal properties. In this study, ACE-inhibitory peptides of S.horrens generated through enzymatic hydrolysis using Alcalase were isolated. Three peptides EVSQGRP, CRQNTLGHNTQTSIAQ and VSRHFASYAN were found to exhibit high inhibition potency with $\mathrm{IC}_{50}$ values of $0.05,0.08$ and $0.21 \mathrm{mM}$, respectively. It was found that the EVSQGRP, VSRHFASYAN and SAAVGSP exhibiting mixed inhibition patterns were susceptible to degradation by ACE as well, suggesting that the mixed-mode inhibition could be a result of new generated peptide fragments while CRQNTLGHNTQTSIAQ inhibited ACE in a non-competitive manner. In-vivo ACE inhibition studies showed that $400 \mathrm{mg} / \mathrm{kg}$ of Alcalase-generated proteolysate stabilized the blood pressure in normotensive rats. These results suggest that the hydrolysed protein components of S.horrens possess bioactive peptides that can be exploited as functional food ingredients against hypertension.
\end{abstract}

Keyword: ACE-inhibitory peptides; Hypertension; Medicinal sea cucumber; Mode of inhibition; Isoelectric focusing technique; In vivo ACE inhibition assay 